\title{
Utility of dried serum spots for triglyceride estimation
}

\author{
Reshma D. C. ${ }^{1}$, Anuradha Patil',* \\ ${ }^{\mathbf{1}}$ Assistant Professor, ${ }^{2}$ Professor \& HOD, Dept. of Biochemistry, KLE Academy of Higher Education and Research (KAHER), \\ Jawaharlal Nehru Medical College, Belgaum, Karnataka, India
}

*Corresponding Author:

Email: dranura9@gmail.com

Received: $06^{\text {th }}$ January, 2018

Accepted: $28^{\text {th }}$ February, 2018

\begin{abstract}
In a developing country like India, screening the population of remote areas for Non Communicable Diseases is difficult because of less availability of infrastructure and technical staff. It is ideal to carry out the analysis in a good quality central laboratory, but the transportation of samples in cold chain is of concern. Dried serum spot technology has various advantages compared to conventional serum analysis, it helps in convenient shipment of samples at low cost without the requirement of cold chain. Problems with leaking and spilling of liquid serum samples will not happen. Stability of analytes will be improved. Serum spot analysis is therefore a convenient method for screening the population presenting with health risks. This study was undertaken to look for stability of triglycerides in serum dried on filter paper at room temperature for different time intervals.100 Samples of Patients coming to the laboratory of KLE Hospital Belgaum were analysed for Triglyceride levels. The remaining serum was spotted onto 3M Whattman filter paper and left at room temperature for an hour for drying. Subsequently dried serum spots were analysed for Triglyceride levels on 0, 7, 14, 21, 28 and 35 days in a Erba semi autoanalyser using commercially available kit.The comparable values obtained from dried serum spots makes it a reliable and convenient method for screening modifiable risk factors like Triglyceride levels.
\end{abstract}

Keywords: Dried serum spots, 3M Whatmann filter paper, Screening, Triglyceride estimation.

\section{Introduction}

Guthrie and Susi introduced the method of blood sample collection on filter paper in 1963. It is a simpler way of sample collection with easy transport and storage of the samples as they are dried. ${ }^{1}$ In general, any analysis that can be done using whole blood, serum or plasma can also be done from dried serum on filter paper. The dried serum stabilizes many analytes and hence their measurement from less volume of sample is possible. ${ }^{2}$ The method of dried serum spots on filter paper is comparable in precision and reproducibility with the results obtained by traditional venepuncture method for collecting blood. ${ }^{3}$

The advantages of using Dried serum spots over the routinely used serum sample analysis are, it helps in easy transport of samples at lesser cost without the requirement of cold chain. Problems with leakage and spilling of liquid samples will not happen. Analytes will be much stable and viruses causing infection are destroyed as serum is dried. Samples are stable for longer time at room temperature, without cold storage facilities for transport and storage. ${ }^{4}$ Indians with Coronary Artery Diseases have similar cholesterol levels as western subjects but triglyceride levels are much higher. High Triglyceride levels lead to changes in LDL particles their size, density, distribution, and composition, which in turn enhances the production of small dense atherogenic particles. ${ }^{5}$

Large multicentric studies are being done to reassess the importance of triglyceride levels in Indian population. These studies are facing difficulties in carrying out laboratory investigations. Options are to perform the investigations at each remote centre or the samples to be transported to a central laboratory. If investigations are carried out at various remote centres it results in lot of variations in results obtained. Whereas carrying out investigations at central laboratory has the problems related to transportation like contamination, leakage and spillage of liquid serum samples as several days are required for samples to reach the central laboratory. A suitable method for transporting samples is therefore an important requirement for analysis to be carried out at a central laboratory.

Triglycerides are known modifiable risk factors for cardiovascular diseases..$^{6-8}$ Quraishi et al.-have reported a triglyceride determination method in dried blood spots and have demonstrated that levels were stable for 30 days at $16-28^{\circ} \mathrm{C}$ and for 90 days at $4^{\circ} \mathrm{C} .{ }^{9}$ Triglyceride measurements from dried blood have been reported previously under controlled laboratory conditions..$^{9-11}$ A community-based cross-sectional study for NCD risk factor surveillance was conducted in six centers spread across the country viz. Ballabgarh, Chennai, Dibrugarh, Nagpur, Trivandrum, and New Delhi (IHBAS) from 2004 to 2005. They concluded that dried blood would offer an excellent method for collection of blood for measurement of triglycerides for population surveys ${ }^{5}$ Dried spot sampling represents a method being adopted by a growing number of population-based studies, internationally. For many biomarkers, it provides a viable alternative to using venipuncture, particularly as the list of analytes that can 
be quantified from dried serum spot samples is growing. ${ }^{12}$

There is a need in our country for considering this method as there is a large rural population and less availability of resources and technical capacity. Method should be standardised by a responsible authority and quality materials should be provided. Basic knowledge regarding spotting and storage of samples should be given to healthcare workers.

\section{Materials and Methods}

100 Blood Samples available at the laboratory of KLE Hospital, Belgaum, were taken and serum was separated. Hemolysed samples were excluded. Analysis was done according to the details mentioned by Lakshmy Ramkrishnan et al. ${ }^{10}$ An aliquot of fresh serum sample was analyzed immediately for Triglyceride levels with the commercially available kits in a semiautoanalyser. For estimation of triglycerides in fresh serum, $10 \mu \mathrm{L}$ was added to $1 \mathrm{ml}$ of reagent and the reaction was carried out at $37^{\circ} \mathrm{C}$ for 10 mins. From the remaining serum, exact $10 \mu \mathrm{L}$ replicates of the serum samples were spotted onto $3 \mathrm{M}$ Whattman filter paper kept on a nonabsorbent surface (thermacol) and left at room temperature for $1 \mathrm{~h}$ for drying.

After drying, one aliquot was eluted and analyzed on the same day of collection. The remaining filter discs were kept in a sealed plastic bag to protect them from dust and moisture and stored at room temperature for different time periods. At 7, 14, 21, 28 and 35 days, entire dried serum spots corresponding to $10 \mu \mathrm{L}$ were cut out with scissors and transferred to $1.0 \mathrm{ml}$ of enzymatic reagent and the reaction was carried out for 30 min (according to Lakshmi Ramkrishnan et al ${ }^{10} 10$ min will not be sufficient for the reaction to reach completion). Analysis was done using Erba semiautoanalyser. Methanol can be used for elution of Triglycerides from dried spots. Precautions are needed for proper spotting, complete drying and proper storage to protect samples from dust, moisture and other contaminants. Careful cutting out of sample spots and complete elution of analyte has to be done.

\section{Results}

Triglyceride values in the 100 samples ranged from $86 \mathrm{mg} / \mathrm{dl}$ to $168 \mathrm{mg} / \mathrm{dl}$. The mean \pm standard deviation (SD) of triglyceride values obtained from fresh serum was $113.18 \pm 18.78 \mathrm{mg} / \mathrm{dl}$ and the mean triglyceride values from corresponding dried serum was $112.78 \pm$ $18.63 \mathrm{mg} / \mathrm{dl}$ on the same day of drying and subsequently $112.52 \pm 18.63$ (day 7), $112.35 \pm 18.64$ ( day14), $111.87 \pm 18.71$ (day 21), $111.63 \pm 18.72$ (day 28 ) and $111.49 \pm 18.80$ (day 35).

Table 1: Summary of variables by different time points

\begin{tabular}{|l|c|c|c|c|c|c|c|c|}
\hline \multicolumn{1}{|c|}{ Statistics } & Min & Max & Range & Mean & SD & SE & Median & IQR \\
\hline Day 0 (fresh) & 86.00 & 168.00 & 82.00 & 113.18 & 18.78 & 1.88 & 110.00 & 12.25 \\
\hline Day 0 (dried) & 86.00 & 168.00 & 82.00 & 112.78 & 18.63 & 1.86 & 110.00 & 12.25 \\
\hline Day 7 & 84.00 & 168.00 & 84.00 & 112.52 & 18.63 & 1.86 & 110.00 & 11.50 \\
\hline Day 14 & 84.00 & 168.00 & 84.00 & 112.35 & 18.64 & 1.86 & 110.00 & 11.50 \\
\hline Day 21 & 84.00 & 166.00 & 82.00 & 111.87 & 18.71 & 1.87 & 109.00 & 12.50 \\
\hline Day 28 & 84.00 & 166.00 & 82.00 & 111.63 & 18.72 & 1.87 & 109.00 & 12.50 \\
\hline Day 35 & 84.00 & 166.00 & 82.00 & 111.49 & 18.80 & 1.88 & 108.00 & 12.50 \\
\hline
\end{tabular}

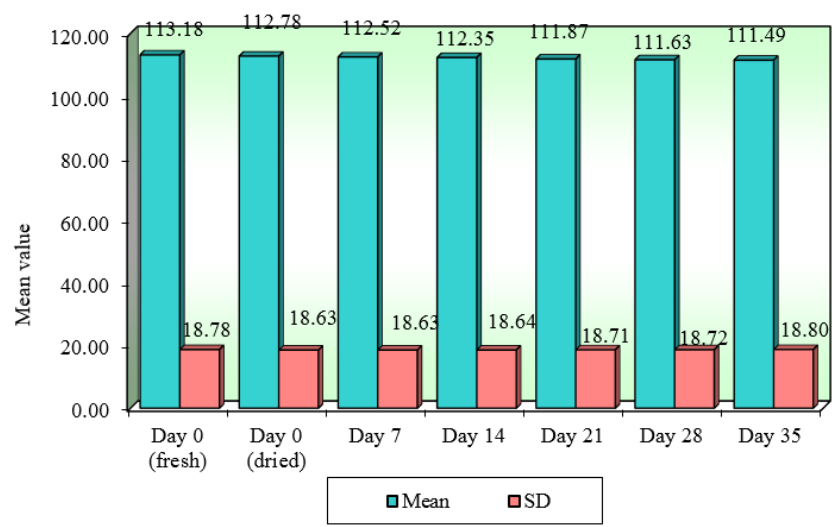

Fig. 1: Comparison of Triglyceride scores at different time points

Change scores of Triglyceride levels from day 0 to day 35 did not follow a normal distribution; therefore, nonparametric Wilcoxon matched pairs test was applied which gave a p value of less than 0.05 . 
Table 2: Comparison of different time points with Triglyceride scores by Wilcoxon matched pairs test

\begin{tabular}{|l|c|c|c|c|c|c|c|}
\hline $\begin{array}{c}\text { Time } \\
\text { points }\end{array}$ & Mean & SD & $\begin{array}{c}\text { Mean } \\
\text { Diff. }\end{array}$ & $\begin{array}{c}\text { SD } \\
\text { Diff. }\end{array}$ & $\begin{array}{c}\text { \% of } \\
\text { change }\end{array}$ & Z-value & p-value \\
\hline $\begin{array}{l}\text { Day 0 } \\
\text { (fresh) }\end{array}$ & 113.18 & 18.78 & & & & & \\
\hline $\begin{array}{l}\text { Day 0 } \\
\text { (dried) }\end{array}$ & 112.78 & 18.63 & 0.40 & 0.79 & 0.35 & 4.0145 & $0.0001^{*}$ \\
\hline $\begin{array}{l}\text { Day 0 } \\
\text { (fresh) }\end{array}$ & 113.18 & 18.78 & & & & & \\
\hline Day 7 & 112.52 & 18.63 & 0.66 & 0.97 & 0.58 & 5.0119 & $0.0001^{*}$ \\
\hline $\begin{array}{l}\text { Day 0 } \\
\text { (fresh) }\end{array}$ & 113.18 & 18.78 & & & & & \\
\hline Day 14 & 112.35 & 18.64 & 0.83 & 1.01 & 0.73 & 5.6454 & $0.0001^{*}$ \\
\hline $\begin{array}{l}\text { Day 0 } \\
\text { (fresh) }\end{array}$ & 113.18 & 18.78 & & & & & \\
\hline Day 21 & 111.87 & 18.71 & 1.31 & 0.96 & 1.16 & 7.1149 & $0.0001^{*}$ \\
\hline $\begin{array}{l}\text { Day 0 } \\
\text { (fresh) }\end{array}$ & 113.18 & 18.78 & & & & & \\
\hline Day 28 & 111.63 & 18.72 & 1.55 & 0.85 & 1.37 & 7.7216 & $0.0001^{*}$ \\
\hline $\begin{array}{l}\text { Day 0 } \\
\text { (fresh) }\end{array}$ & 113.18 & 18.78 & & & & & \\
\hline Day 35 & 111.49 & 18.80 & 1.69 & 1.35 & 1.49 & 7.7700 & $0.0001^{*}$ \\
\hline
\end{tabular}

$* \mathrm{p}<0.05$

An Intra class correlation coefficient of 0.99 for triglycerides was evident between dried serum spots and fresh serum. Bland Altman plots were done with Mean of Triglycerides values on $\mathrm{x}$ axis against differences in triglycerides values between fresh serum and dried serum on all $(0,7,14,21,28$ and 35 )days . Bland-Altman plots suggest that the difference in values obtained by the two methods were within 2 SD limits for most of the values of Triglycerides. Less than $5 \%$ of the values were outside the 2 SD limits. ${ }^{13}$

Fig. 2: Bland Altman plot for Triglyceride values in fresh and dried serum

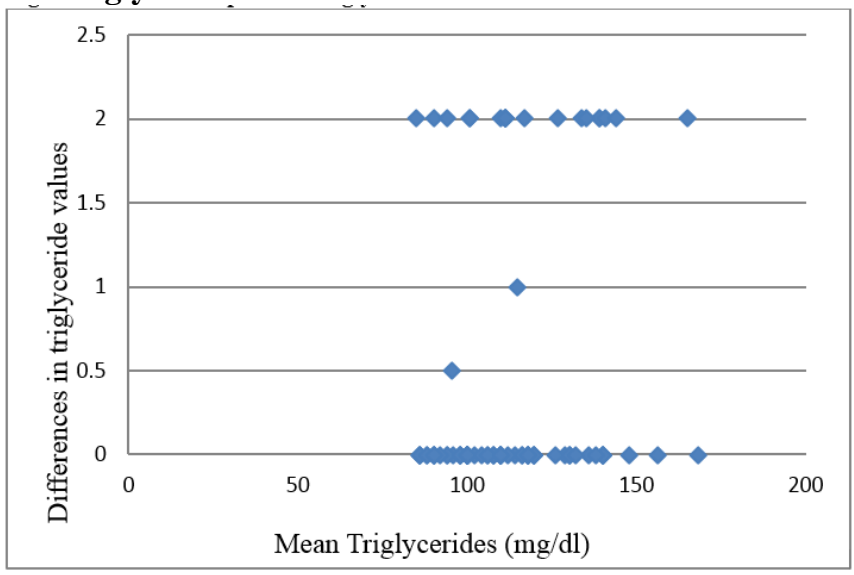

Tonks and Barnett have published estimates of medically allowable error for critical decision levels. Tonks criteria are general (smaller of one fourth of the normal range or $10 \%$ of the measured value. Barnetts recommendations are widely used but are limited to common laboratory analytes. Westguard has transformed Barnetts limits to $95 \%$ limits of allowable error i.e $95 \%$ of patients should have errors less than the limit, or only 1 of every 20 samples can have an error larger than the specified limit[14]. The triglyceride values estimated from dried serum spots compared to that of fresh serum sample were within medically allowable error.

\section{Discussion}

Despite of benefits provided by dried serum spot sampling, there are various hurdles in adopting Dried Serum spot technology for a number of reasons. The first is unpredictability: quite simply, fear of the unknown. The second reason is status quo bias: it is not comfortable changing a method that is already working. 
The third reason is data comparability loss: concern for a potential discrepancy between older data from serum analysis with the newer data from dried serum spots. Finally, the lack of clear regulatory guidance: there is virtually no authoritative literature on the subject of adopting dried serum spot model. ${ }^{15}$

The analysis of dried serum spot samples is similar to serum analysis, with some important changes. As the sample is dried on filter paper, analytes have to be brought into solution. The serum spots are cut out with scissors and put into an elution reagent for a fixed amount of time. Different assay systems and specific analytes will vary in their sensitivity to potential interference, and some assays may require additional processing prior to analysis. ${ }^{16}$

Many standard clinical assays are performed on automated, high-throughput analyzers designed for use with fresh serum samples. These instruments offer increased speed and reduced costs of analysis but currently are not likely to accommodate dried samples. ${ }^{12}$ Furthermore, Investigators can expect performance that is comparable to that obtained with fresh serum samples, this may not always be possible. In such cases, the benefits of dried spot method with regard to sample collection and handling will have to be weighed against the degree of potential error introduced during sample analysis. ${ }^{12}$

Minimization of preanalytical variations with proper collection of serum spots and storage are important determinants for the success of mass screening of triglycerides using dried serum spots for risk factor assessment.

Serum can be stored at $-20^{\circ} \mathrm{C}$ in a non-self defrosting freezer for up to 4 weeks. For longer storage (> 4 weeks) they should be maintained at $-80^{\circ} \mathrm{C}$ or lower. Triglycerides are stable for at least one year at $80^{\circ} \mathrm{C}$ or lower. Whereas dried serum spots can be stored at room temperature for upto 35 days, according to our study. We found that triglycerides are highly stable in dried serum and are readily transferable to liquid phase. The good agreement between values in dried serum and fresh serum supports the use of Triglyceride measurement in dried serum spots.

\section{Conclusion}

This study assessed the usage of dried serum spots for measurement of triglycerides, recognized as modifiable risk factors for cardiometabolic diseases. Dried serum spot technology has various advantages compared to conventional serum analysis, it helps in convenient shipment of samples at low cost without the requirement of cold chain. Problems with leaking and spilling of liquid serum samples will not happen and the stability of analytes will be improved. The comparable values between dried serum spot and fresh serum assays supports the usage of dried serum spot sample collection method as an alternative when facilities are not available or accessible.

\section{References}

1. Williams S R, McDade T W. The Use of Dried Blood Spot Sampling in the National Social Life, Health,and Aging Project. J Gerontol B Psychol Sci Soc Sci. 2009 Nov;64B (Suppl 1):131-6.

2. McCabe, E. R. B. Utility of PCR for DNA analysis from dried-blood spots on filter paper blotters. PCR Methods Appl. 1991(1) 99-106.

3. Mei JV, Alexander JR, Adam BW, Hannon WH. Use of filter paper for the collection and analysis of human whole blood specimens. J Nutr. 2001;131(5):1631S-6S.

4. Kapur S, Kapur S, Zava D. Cardiometabolic Risk Factors Assessed by a Finger Stick Dried Blood Spot Method. J Diabetes Sci Technol. 2008 Mar;2(2):236-41.

5. Lakshmy R, Mathur P .Measurement of cholesterol and triglycerides from a dried blood spot in an Indian Council of Medical Research-World Health Organization multicentric survey on risk factors for non communicable diseases in India. Journal of Clinical Lipidology 2012 (6), 33-41.

6. Sprecher DL. Triglycerides as a risk factor for coronary artery disease. Am J Cardiol.1998;82(12A):49U-59U.

7. Castelli WP. Cholesterol and lipids in the risk of coronary artery disease- the Framingham Heart Study. Can J Cardiol. 1988;4 Suppl A:5A-10A.

8. Dennis LS. Triglyceride as a risk factor for coronary artery disease. Am J Cardio. 1998;82:49U-59U.

9. Quraishi R, Lakshmy R, Prabhakaran D, Mukhopadhyay AK, Jailkhani B. Use of filter paper stored dried blood for measurement of triglycerides. Lipids Health Dis. 2006;5:20.

10. Ramakrishnan L, Reddy KS, Jailkhani BL. Measurement of cholesterol and triglycerides in dried serum and the effect of storage. Clin Chem. 2001; 47(6):1113-5.

11. Quraishi R, Lakshmy R, Prabhakaran D, Irshad M, Mukhopadhyay AK, Jailkhani BL. Effect of storage temperature on cholesterol measurement from dried blood. Indian J Med Res. 2007;126(3):228-9.

12. Mcdade T W, Williams S, Snodgrass J J. What a drop can do: dried blood spots as a minimally invasive method for integrating biomarkers into population-based research. Demography, 2007 Nov;44(4):899-925.

13. Bland JM, Altman DG. Measuring agreement in method comparison studies. Stat Methods Med Res 1999;8:13560.

14. Cembrowski G S, Sullivan A M. Chapter 4: Quality control and statistics. Bishop M L, Duben J L, Laufen V, Fody E P. Clinical chemistry : principles, procedures, correlations. Lippincott Williams \& Wilkins. Edition, Page 74

15. Dhungana S, Meng M, Allen M S. Boost Drug Discovery Efficiency - Switching from Plasma to Dried Blood Spots [Available at http://www.tandemlabs.com/documents/DBS_WhitePape r_Final.pdf]

16. Ahluwalia, N. Diagnostic utility of serum transferrin receptors measurement in assessing iron status. Nutr. Rev. 1998 May;56:133-41. 